\title{
Critical illness outcome study: an observational study of protocols and mortality in intensive care units
}

This article was published in the following Dove Press journal:

Open Access Journal of Clinical Trials

23 September 201I

Number of times this article has been viewed

\author{
Naeem A Ali' \\ David Gutteridge ${ }^{2}$ \\ Sajid Shahul ${ }^{3}$ \\ William Checkley ${ }^{4}$ \\ Jonathan Sevransky ${ }^{4}$ \\ Greg S Martin² \\ 'The Ohio State University Medical \\ Center, Columbus, $\mathrm{OH}$; \\ ${ }^{2}$ Emory University, Atlanta, GA; \\ ${ }^{3}$ Beth Israel Deaconess Medical \\ Center, Boston, MA; ${ }^{4}$ Johns Hopkins \\ University, Baltimore, MD, USA
}

\begin{abstract}
Individual intensive care unit (ICU) characteristics including staffing, expertise, continuity, and team structure, have been associated with patient outcomes. Separately, some aspects of care in ICUs have been implemented through treatment protocols. The United States Critical Illness and Injury Trials Group-Critical Illness Outcomes Study (USCIITG-CIOS) was designed to determine whether the extent of protocol use in ICUs is associated with hospital survival in a large number of US ICUs. Here, we describe the study protocol and analysis plan approved by the USCIITG-CIOS steering committee. USCIITG-CIOS is a prospective, observational, ecological, multicentered study of mixed ICUs in the US. The data to be collected include organizational information for the ICU (eg, protocol availability and utilization, multidisciplinary staffing assessment), and patient level information (eg, demographics, acute and chronic medical conditions). The primary outcome is all-cause hospital mortality, with the objective being to determine whether there is an association between protocol number and hospital mortality for ICU patients. USCIITG-CIOS is powered to detect a $3 \%$ difference in crude hospital mortality between high-protocol and low-protocol use ICUs, dichotomized according to protocol number at the median. The analysis will utilize multivariable regression approaches to adjust for outcome clustering by ICU, with secondary linear analysis of protocol number and mortality and a variety of a priori planned ancillary studies. We anticipate at least 60 ICUs participating in USCIITG-CIOS to enroll approximately 6000 study subjects. USCIITG-CIOS is a multicenter study examining the effect of ICU protocols on patient outcomes. These results will inform our understanding of the relationship between protocol availability, use, and patient outcomes in the ICU. Given the shortage of intensivists worldwide, the results of USCIITG-CIOS can be used to promote more effective and reproducible ICU care and outcomes.
\end{abstract}

Keywords: intensive care, critical care, outcomes, protocols, organization

\section{Introduction}

Critically ill patients are managed in intensive care units (ICUs) that contain limited, focused clinical resources and high-intensity nurse and physician staffing. While ICUs were initially developed to care for all patients with high acuity illness on a single hospital ward, they have evolved over the past 50 years to include units for patients with general respiratory failure or those with more narrowly defined illnesses or injuries in subspecialty ICUs. ${ }^{1}$ Anecdotal and published reports indicate that there is wide variation in the organization and structure of these units. For example, variation has been documented in physician staffing, hours of staffing, the presence and role of medical directors, and the presence of multidisciplinary rounding teams. ${ }^{2-5}$ Heterogeneous care provided to ICU patients may be related in part to patient differences or a lack of
Correspondence: Greg S Martin

Division of Pulmonary, Allergy and

Critical Care, Emory University School

of Medicine, Atlanta, GA, USA

$\mathrm{Tel}+\mathrm{I} 4046160148$

Email greg.martin@emory.edu
Open Access Journal of Clinical Trials 201 I:3 55-65

(C) 20I I Ali et al, publisher and licensee Dove Medical Press Ltd. This is an Open Access article

Dovepress

http://dx.doi.org/10.2147/OAJCT.S24223 
medical consensus. However, some of this variation in care may be related to the general characteristics of the ICU itself and the practitioners who work there. ICU factors previously shown to be associated with practice variation include ICU type (general or specialty), location, and the training of the lead physician. ${ }^{6,7}$ Whether this heterogeneity leads directly to worse outcomes (cause and effect) remains to be proven; however, variation in patients admitted to specialty ICUs that do not match their particular diagnosis appear to fare worse, suggesting that familiarity and possible standardization of care may influence patient outcomes. ${ }^{7-9}$

One method for reducing unwanted variance in clinical practice is the use of treatment protocols to drive care for patients meeting specific criteria. ${ }^{10}$ There is little information on whether differences in processes of care (previously attributed to ICU organization and structure) might be related to the use of protocol-based care. For instance, high-intensity ICU organization has been shown to be associated with higher likelihood of evidence-based delivery of low tidal volume ventilation to acute lung injury patients. ${ }^{6}$ However, the presence of a protocol has also been linked to more frequent use of a desired process of care $^{11}$ and therefore is likely to be associated with improved patient outcomes. As a result, it is logical to expect that a greater number of protocols is associated with a reduction in unwanted practice variation and thereby improved outcomes independent of ICU organization. The United States Critical Illness and Injury Trials Group (USCIIT Group) designed the Critical Illness Outcomes Study (USCIITG-CIOS) to test the hypothesis that the number of protocols influences hospital mortality.
Additionally, this study will determine the prevalence of protocols in 60 ICUs in the US.

\section{Methods \\ Study design}

To test the hypothesis that the number of protocols used in an ICU is associated with hospital survival, the USCIIT group has organized a large prospective observational study of ICU patients. Initial ICUs will be selected from a range of institutions participating in USCIIT group and other collaborative groups. After recruitment, physicians familiar with each ICU will be asked to fill out a structured assessment of protocol use and general unit characteristics, including physician and nursing staffing, the presence of electronic medical records and computerized order entry. This survey will determine both the presence of a priori defined care protocols and how they are utilized. In addition, respondents will have the opportunity to report self-determined protocols. Clinical characteristics and outcomes of a series of patients in these same ICUs will then be recorded (Figure 1).

At the time of initial planning, several important substudies were integrated into the overall study design, ie, ICU staffing patterns, the presence of electronic medical records, and continuity of care measurements. Adherence to specific care protocols and their relationship to diseasespecific outcome will also be determined (Table 1).

\section{Site recruitment and communications}

Because health care delivery systems and intensive care units vary between countries, we sought to identify at least 60 ICUs

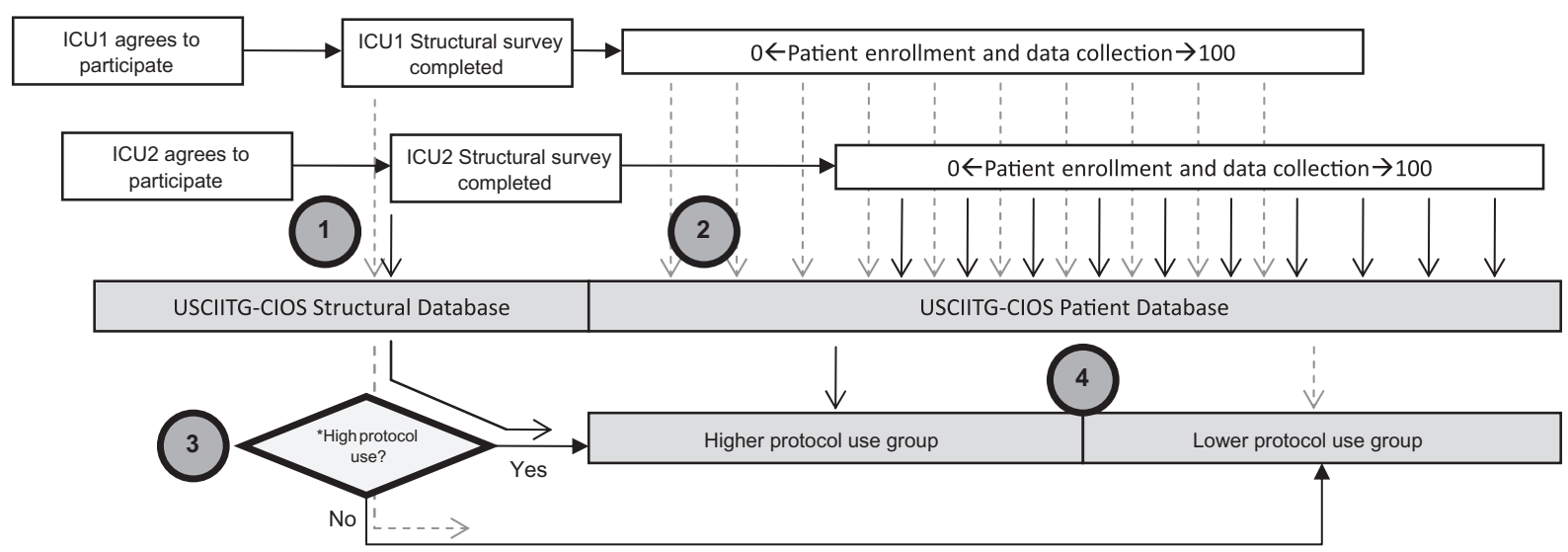

Figure I Study scheme and sequence of data submission. (I) Individual sites entered the study independently and submission of structural survey information was required prior to patient enrollment. Individual ICUs were then assigned to a high protocol group or low protocol group according to their specific number of protocols relative to the median for the study. (2) Patient data is entered by individual sites without the knowledge of whether their ICU is defined as high protocol or low protocol use (3) as the group assignments are made centrally at the conclusion of the study. This same procedure was followed for all 60 centers. In this example, ICUI was defined as a "lower" protocol ICU and ICU2 as a "higher" protocol site. Numbers indicate sequence of activities.

Note: *Assigned at the conclusion of data entry.

Abbreviations: ICU, intensive care unit; USCIITG-CIOS, United States Critical IIIness and Injury Trials Group Critical IIIness Outcomes Study. 
Table I Partial list major planned substudies under USCIITG-CIOS

\begin{tabular}{|c|c|c|}
\hline Title & Description & Investigators \\
\hline Systematic review of protocols & $\begin{array}{l}\text { Systematic review of protocol efficacy for } \\
\text { improving patient outcomes }\end{array}$ & $\begin{array}{l}\text { Patil, Eberlein, Winters, Morris, Brown, } \\
\text { Hirschburg, Prasad }\end{array}$ \\
\hline ICU structure & Descriptive phenotype of USCIITG-CIOS centers & Checkley, Sevransky, Gajic, Howell, Shahul \\
\hline $\begin{array}{l}\text { Race/ethnicity, processes and } \\
\text { outcomes in the ICU }\end{array}$ & $\begin{array}{l}\text { Analysis of the association between race or ethnicity and } \\
\text { receipt of health care and associated outcomes, adjusting for } \\
\text { confounders }\end{array}$ & $\begin{array}{l}\text { Martin, Pietropaoli, Howell, Shahul, } \\
\text { Talmor, Hunziker }\end{array}$ \\
\hline Transfusion goals & Do we comply with transfusion protocols? & Murphy, Shahul \\
\hline Epidemiology of FFP transfusion & Description of frequency and triggers for FFP transfusion & Netzer, Shahul \\
\hline EMR and ICU & $\begin{array}{l}\text { Is there a patient-level benefit to health information } \\
\text { technology in the ICU? }\end{array}$ & $\begin{array}{l}\text { Pickering, Howell, Talmor, Han, Shahul, } \\
\text { Pickering, Hunziker }\end{array}$ \\
\hline Cancer & Prevalence and outcomes & Eberlein, Pastores \\
\hline Consultation & $\begin{array}{l}\text { Epidemiology of consultative services in critically ill patients } \\
\text { in the US }\end{array}$ & Howell, Talmor, Goodspeed \\
\hline Continuity of care & Does a change in resident or attending influence care delivery? & Siner, Gutteridge \\
\hline Nutrition & Prevalence of adequate nutrition in ICUs & Rice, Shahul \\
\hline ALI/MODS simulation model & $\begin{array}{l}\text { Validation of a multiscale simulation model of acute lung injury and } \\
\text { multiorgan failure in the multicenter cohort of critically ill patients }\end{array}$ & Gajic, Pickering \\
\hline
\end{tabular}

Abbreviations: EMR, electromagnetic resonance; FFP, fresh frozen plasma; ICU, intensive care unit; USCIITG-CIOS, United States Critical IIIness and Injury Trials Group Critical Illness Outcomes Study; ALI/MODS, acute lung injury/multiple organ dysfunction syndrome.

in the US only. Sites will be initially petitioned by review of publications from active critical care investigators in the US, word-of-mouth at international critical care meetings, and direct communication with previous collaborators. Specific communication was sent to representatives of the USCIIT Group and Surviving Sepsis Campaign institutions. Both academic and nonacademic ICUs were approached, regardless of specialty (eg, medical, surgical, cardiac, neurologic, trauma) and case-mix (eg, cancer). Follow-up calls provided a more detailed discussion between a USCIITG-CIOS principal investigator and the local contact at the site. During this semistructured interview, local ICU structure referral patterns, prior clinical research experience, the USCIITG-CIOS study protocol, anticipated workflow, workload, expectations, and site principal investigator rights were discussed. Interested sites were provided with basic Institutional Review Board application materials and ultimately access to the USCIITG-CIOS web interface. Over 70 sites progressed to phone interview, with all sites committing to data collection and study protocol requirements being invited to participate. Only two sites were excluded due to inability to obtain Institutional Review Board approval.

Communication between the principal investigators and individual site investigators is logistically complex. Formal communication from the USCIITG-CIOS principal investigators to site investigators will begin at the time of first subject recruitment through a variety of media. These include face-to-face meetings, conference calls, and electronic LISTSERV communications (Figure 2). Regularly scheduled emails will provide updates on recruitment status, deadlines, and overall study progress. Intersite communication is encouraged. Site-specific queries will be handled by the principal study investigators via electronic communication. Final participating sites are listed in Appendix A.

\section{Study subject and human subject protections}

Each site will be asked to screen census registers weekly to enroll new ICU patients. Sites are permitted discretion in choosing survey days and encouraged to rotate days to ensure variation in sampling. Study subjects are defined as adult patients occupying a bed in the study ICU at 8 am on each survey day. Subjects were excluded if they were $<18$ years of age or had been previously enrolled into USCIITG-CIOS. Enrollment days will not be continuous in order to facilitate subject enrollment without duplication. A minimum of 100 subjects was targeted for enrollment from each study ICU (Figure 3).

Because the exposure of interest (indigenous clinical care protocols) will be by definition, the baseline practice of any individual unit, and these practices will not be altered by study participation, any variation across study sites is considered local "usual care". In addition, this study was designed to collect all patient information devoid of personally identifiable indicators. As a result, local institutional review boards will be petitioned for a waiver of consent. 


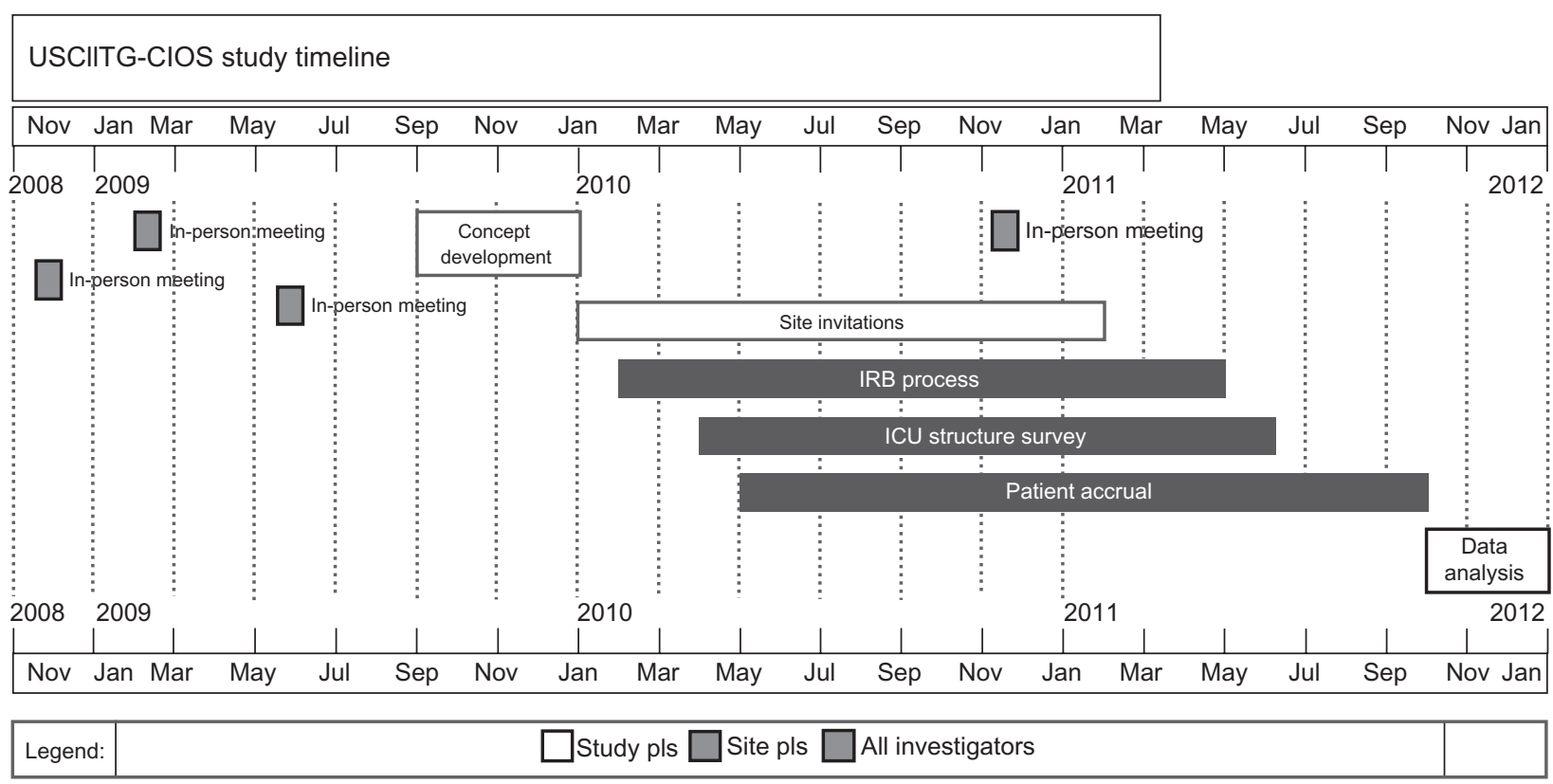

Figure 2 Study history timeline. Because so many sites were recruited, the process of site engagement, approval and initiation occurred in a "rolling" fashion. In-person meetings and electronic communication was used to attempt to compress the time window during which surveys were completed and patients enrolled.

Abbreviation: Pls, principal investigators.

\section{Sample size}

The primary objective of this study is to determine if a difference in hospital mortality exists between highly protocolized ICUs and those with fewer or no protocols. Because no threshold number of protocols could be proposed from prior work, we chose to divide ICUs into two groups defined by the median number of protocols observed in our sample of ICUs (median to be determined). We estimated that the minimal significant difference in unadjusted mortality outcomes would be $3 \%$ between ICU with a "higher" and "lower" number of protocols. Based upon average mortality from surveys of individual ICUs, we assumed that the group

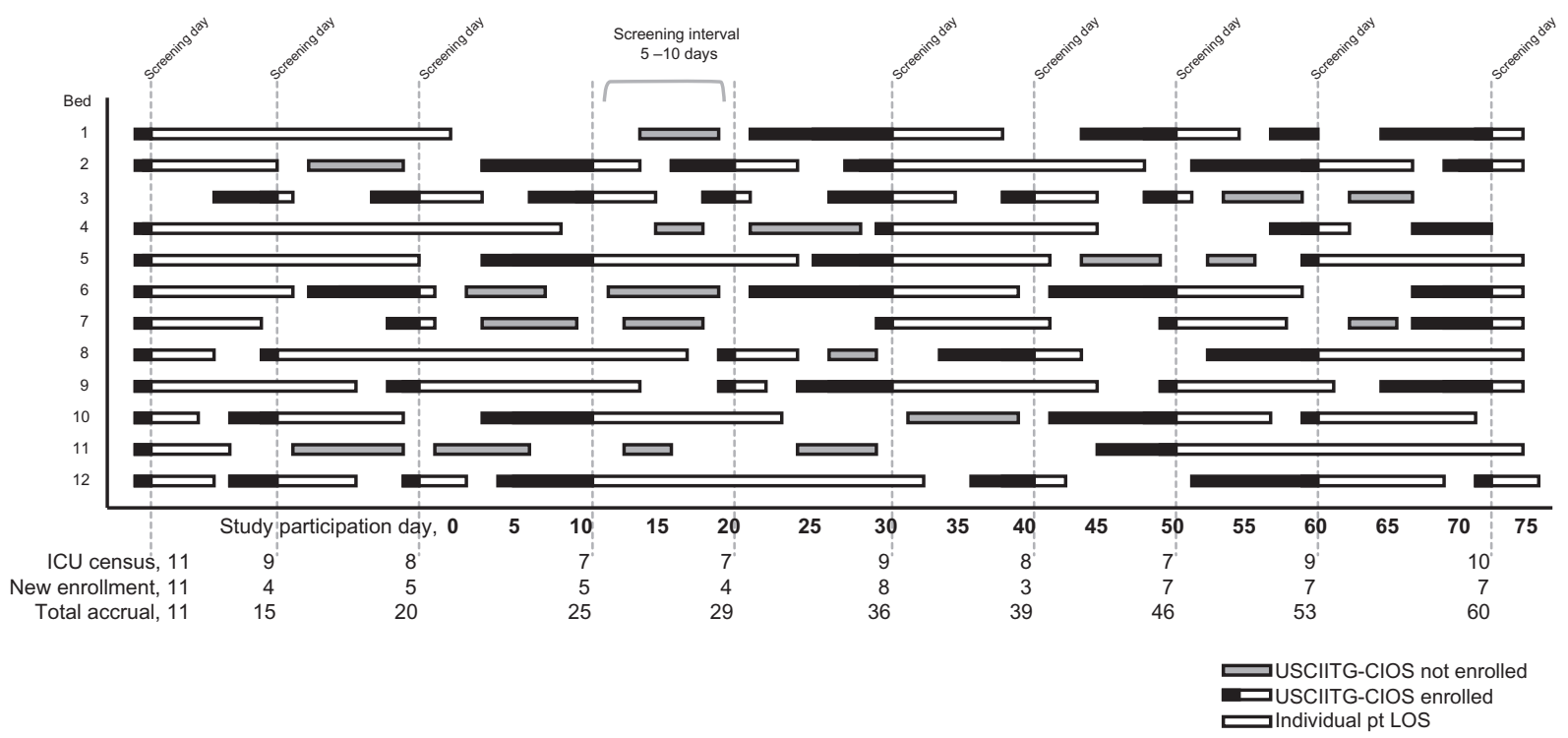

Figure 3 Patient accrual scheme. This illustrates the hypothetical patient accrual into the USCIITG-CIOS study from a single participating ICU with twelve patient care beds. ICU census registers were screened at intervals that varied between 5 and 10 days. All patients were eligible for data entry unless they were previously entered or met other exclusion criteria. The black portion of a patient stay bar indicates their enrollment in the USCIITG-CIOS patient database and the fact that patients are only entered once into the database. All enrolled subjects were followed for outcome data until the time of hospital discharge.

Abbreviations: USCIITG-CIOS, United States Critical Illness and Injury Trials Group Critical Illness Outcomes Study; ICU, intensive care unit; LOS, length of stay in intensive care; pt, patient. 
of ICUs with a lower number of protocols would have a baseline hospital mortality of $15 \%$. Ignoring clustering by ICU, we would require 2791 participants per study group to detect a $3 \%$ absolute difference in hospital mortality, with $90 \%$ power and a significance level of 0.05 . We plan to engage at least 60 centers to accrue 6000 evaluable patients. We anticipate that one year will be required to enroll the requisite number of subjects.

\section{Study outcomes and data collection}

The primary outcome for the USCIITG-CIOS study is hospital mortality. Secondary outcomes are ICU mortality, discharge location, hospital ICU length of stay, and duration of mechanical ventilation. Observations will be recorded using two separate questionnaire case report forms, ie, one for ICU structural data and one for patient-level data. Each participating ICU will complete a structural questionnaire prior to enrolling subjects. The structural questionnaire includes 79 questions in seven sections, comprising general information, bed count, utilization, staffing, rounding practices, team work tools, and ICU protocols (Table 2). A "protocol" will be defined using the Medline MeSH subject heading as "precise and detailed plans for a regimen of therapy". Investigators will be left to determine whether local practice was guided by a protocol, but additional questions will be asked to determine how the protocol was activated and how its recommendations were implemented. Guidance for the survey will be provided in the distributed operations manual. After the structural questionnaire is deemed complete, the site will be allowed to enroll subjects.

Enrollment days will be chosen randomly, with 5-10 days between enrollments to allow for patient turnover. A case report form will be completed for all patients receiving care in an ICU on the day they meet the enrollment criteria. The case report form includes 136 items organized into nine sections, comprising demographics, illness severity, organ failure

Table 2 Major components of the structural survey

\begin{tabular}{lll}
\hline Domain & $\begin{array}{l}\text { Number of } \\
\text { questions }\end{array}$ & $\begin{array}{l}\text { Structure of } \\
\text { responses }\end{array}$ \\
\hline $\begin{array}{l}\text { Hospital and ICU } \\
\text { overview }\end{array}$ & 16 & $\begin{array}{l}\text { Categorical } \\
\text { and numerical }\end{array}$ \\
Staffing & 10 & $\begin{array}{l}\text { Categorical } \\
\text { and numerical }\end{array}$ \\
Organization & 9 & Categorical \\
Services & 2 & Categorical \\
Rounding practices & 10 & Categorical \\
ICU protocols & 26 & Categorical \\
Teamwork tools & 2 & Categorical \\
\hline
\end{tabular}

Abbreviation: ICU, intensive care unit. data, mechanical ventilation, medications, treatment issues, diagnoses, infections, and outcomes (Table 3). Records will be reviewed on the day of enrollment and periodically thereafter until the time of discharge to obtain appropriate treatment and follow-up data. Admission data on mechanical ventilation and medications will be recorded from 8 am on the day of enrollment. All other data are based on the 24-hour period prior to enrollment (Table 3 ).

Patient charts will be reviewed for documented chronic organ insufficiency and the circumstances leading to ICU admission. These categorizations and their definitions will be recorded according to Acute Physiology and Chronic Health Evaluation II definitions. ${ }^{12}$ Researchers are not permitted to interpret records; diagnoses recorded in the case report form are all based upon physicians' or other practitioners' notes recorded in the patient's chart. The presence of chart documentation and consult notes will be recorded in order to quantify the number of disciplines involved in each patient's care. These notes will be defined as identifying a specific service by the title of the chart entry. Data on infections will be completed based on progress notes from the day of enrollment and the most recent laboratory data. Outcome data will be completed after the patient is discharged from

Table 3 Patient-level data collection

\begin{tabular}{|c|c|c|c|}
\hline Domain & $\begin{array}{l}\text { Number of } \\
\text { questions }\end{array}$ & $\begin{array}{l}\text { Structure of } \\
\text { responses }\end{array}$ & Time frame \\
\hline Demographics & 13 & $\begin{array}{l}\text { Categorical and } \\
\text { numerical }\end{array}$ & $\begin{array}{l}\text { At hospital } \\
\text { admission }\end{array}$ \\
\hline $\begin{array}{l}\text { Severity of } \\
\text { illness }\end{array}$ & 29 & $\begin{array}{l}\text { Categorical and } \\
\text { numerical }\end{array}$ & $\begin{array}{l}24 \text { hours prior } \\
\text { to enrollment }\end{array}$ \\
\hline $\begin{array}{l}\text { Organ failure } \\
\text { data }\end{array}$ & 6 & Numerical & $\begin{array}{l}24 \text { hours prior } \\
\text { to enrollment }\end{array}$ \\
\hline $\begin{array}{l}\text { Mechanical } \\
\text { ventilation }\end{array}$ & II & $\begin{array}{l}\text { Categorical and } \\
\text { numerical }\end{array}$ & $\begin{array}{l}8 \text { am on day } \\
\text { of enrollment }\end{array}$ \\
\hline Medications & 6 & Categorical & $\begin{array}{l}24 \text { hours prior } \\
\text { to enrollment }\end{array}$ \\
\hline $\begin{array}{l}\text { Treatment } \\
\text { factors }\end{array}$ & 22 & Categorical & $\begin{array}{l}24 \text { hours prior } \\
\text { to enrollment }\end{array}$ \\
\hline Diagnoses & 6 & $\begin{array}{l}\text { Categorical and } \\
\text { numerical }\end{array}$ & $\begin{array}{l}24 \text { hours prior } \\
\text { to enrollment }\end{array}$ \\
\hline Infections & 6 & Categorical & $\begin{array}{l}24 \text { hours prior } \\
\text { to enrollment }\end{array}$ \\
\hline Outcomes & 9 & Categorical & $\begin{array}{l}\text { Values recorded } \\
\text { after discharge }\end{array}$ \\
\hline
\end{tabular}

Notes: Instruments and definitions used within the survey include the following: severity of illness, Acute Physiology and Chronic Health Evaluation II; organ failure, Sequential Organ Failure Assessment; coagulopathy, International Normalized Ratio $>1.5$, partial thromboplastin time $>2 \times$ control or platelets $<50,000$; hypotensive, mean arterial pressure $<65 \mathrm{mmHg}$, systolic blood pressure $<90 \mathrm{mmHg}$, or drop in systolic blood pressure of $>40 \mathrm{mmHg}$ despite $2 \mathrm{~L}$ fluid given; delirium, Confusion Assessment Method for the Intensive Care Unit, Intensive Care Delirium Screening Checklist, Nursing Delirium Screening Scale; stress dose steroids, hydrocortisone $\geq 200 \mathrm{mg} /$ day or equivalent dose of other corticosteroids. 
the hospital. Discharge location includes detail about hospital type if the patient is discharged to another inpatient facility. The presence of mechanical ventilation, renal replacement therapy, or limitation-of-care orders at hospital discharge will also be documented.

\section{Primary analysis and other statistical considerations}

The primary objective of this study is to determine whether an association exists between the number of ICU protocols and hospital mortality for ICU patients. The primary outcome for this study is hospital mortality. As described above, we plan to divide ICUs into two groups based upon the median number of protocols observed in the entire sample of ICUs ( $n=30$ as having a higher number of protocols and $n=30$ as having a lower number of protocols). We will first compare the simple means of the hospital mortality rates between the two predefined groups of ICUs using standard techniques. ${ }^{13}$ Secondly, we will perform an adjusted analysis controlling for physiologic severity of illness and other potentially confounding variables. Specifically, we will use logistic regression techniques with generalized estimating equations, a compound symmetry matrix ${ }^{14}$ and a robust variance estimate to adjust for clustering of hospital mortality by ICU. In a secondary analysis, we will characterize the relationship between the number of protocols as a continuous variable and hospital mortality using regression splines ${ }^{15}$ within the context of multivariable logistic regression with generalized estimating equations.

\section{Data quality and management}

Prior to data collection, the principal investigators developed an operations manual to ensure intersite reliability. The operations manual includes selected definitions for questionnaires as well as guidelines for data collection. The operations manual will be maintained and revised as needed by the principal investigators, and distributed to sites as revisions are made. Frequent communications will be sent electronically that include clarifications of the operations manual, discussion of Institutional Review Board approval process, and suggestions regarding data collection. The primary investigators review the structural questionnaire at each site prior to allowing subject enrollment.

All patient data will be recorded on paper case report forms and then entered into an online database maintained by Johns Hopkins University. The database was designed to prevent entry of duplicate patients in the following ways. First, the database will create a unique patient identifier for each new patient based on the demographic information provided. This demographic information will be then compared with enrollees. Subjects with an exact match on five independent variables (gender, age, race, height, and weight) will be blocked from entry. During data entry, computer decision support identifies missing, inconsistent, or out-of-range data. A data error query will be produced and either resolved within the data center by individual, manual review, or returned to the local investigator for resolution. Finally, the database ensures that data is entered in structured formats to facilitate calculation of the APACHE II and Sequential Organ Failure Assessment scores.

\section{Discussion}

We have developed a large collaborative US study to investigate the effect of the number of protocols used in an intensive care unit on hospital mortality. There are many factors that influence outcomes in individual ICUs. These factors can include local referral patterns, ${ }^{16-18}$ patient-specialty ICU type match, ${ }^{7}$ case-volume, ${ }^{8}$ staffing characteristics, and expertise. ${ }^{2,3}$ Presumably, these superficial characteristics belie some variation in the ability to identify or treat important medical issues. Protocols have been used to reduce unwanted practice variation. Protocol-driven interventions in the ICU have improved targeted process measures and disease-specific outcomes, ${ }^{19}$ but the association between the number of protocols and general outcome across diverse patient groups has not been studied. In this multicenter prospective study, we test the hypothesis that there is an association between the amount of protocol-driven practice in a given ICU and outcome.

There is a significant evidence base that should influence ICU practice. Noteworthy practices include transfusion management, ${ }^{20,21}$ sedation and analgesia, ${ }^{22}$ and ventilator weaning. ${ }^{23,24}$ Additionally, condition-specific practices like the use of low tidal volume ventilation in acute lung injury patients $^{25}$ or aggressive treatment of septic shock have improved mortality in these diseases. ${ }^{26}$ Given that these are common ICU conditions and treatments, adopting these practices effectively could improve outcomes across larger populations of general critically ill patients independent of their admitting problem. Despite knowledge of these interventions and their beneficial consequences, evidence suggests these practices are still only variably applied. ${ }^{27-32}$

Nonadherence to recommended protocols can be related to knowledge deficits, distractions ${ }^{33}$ or a lack of access to evidence at the point of care. ${ }^{34}$ Knowledge of these barriers has led to the development of simple checklists for ICU teams 
to use to identify treatment goals, but their ability to improve adherence is dependent on knowledge of a mechanism to effect these goals. ${ }^{35,36}$ Protocols can provide operational definitions for the delivery of evidence-based therapy and accordingly increase a practitioner's ability to understand how to apply a specific practice. When clear and readily available, ${ }^{37,38}$ protocols should improve outcomes in a variety of ways, particularly if baseline adherence to desired practice is low. In some settings, these protocols may improve the efficiency of decision-making or allow the responsibility for the decision to be shifted to appropriate team members.

The organizational structure of an intensive care unit has been linked to adherence to evidence-based ventilator management for acute lung injury patients. ${ }^{6,39}$ Our study will attempt to describe whether one potential mechanism for this effect is the use of protocols. The systematic adoption of protocols, using presence of a higher number of protocols as a proxy, should be associated with improved outcomes because it marks an underlying multidisciplinary culture that defines unwanted practice variation. Alternately, if a specific ICU cares for a high proportion of patients where these practices apply (like sepsis or acute lung injury) then protocols could directly improve practice and outcome. ${ }^{38}$ Finally, a higher number of protocols could simply increase the likelihood of having the "right" protocols in place. In any case, the observation that the number of protocols is associated with outcome could have important implications for the appropriate design and structure of ICU care teams particularly when the human resources needed to develop multidisciplinary teams are limited..$^{40-42}$

The novelty of our study is that it addresses a unique topic in critical care medicine that could not be easily studied in a prospective randomized design. It is clear that multidisciplinary teams improve outcomes in ICUs, ${ }^{5,43}$ but the mechanism by which this occurs is not known. By studying protocol use in general, we are analyzing an approach to care standardization and not the practices themselves. Strengths of our study design include a broad array of ICUs of mixed type and the explicit description of their coverage model and care practices. In addition, data collection was designed not only to quantify protocols but also to record the area of practice they are designed to impact. We record data about how the particular protocol is activated (standing order, individual activation) to understand where in the process of clinical decision-making these support tools exist. Finally, by collecting important clinical data we can generate inferences about what proportion of patients in an individual ICU would have been a candidate for protocoldriven care and appropriately risk-adjust all outcomes.
There are several potential limitations to this study. By including a broad array of ICU types, we may lose the ability to determine the importance of individual care protocols that impact a small proportion of our study patients (eg, ventriculostomy management). Second, because we primarily measure outcome as hospital mortality, we may lose the ability to detect benefit from care protocols that have a greater impact on morbidity than mortality. Examples of these types of treatments include sedation practice and mobility protocols. It is possible that the way in which a protocol is activated is important to its ability to affect outcomes. Because we are only collecting survey data about how protocols are utilized, we lack the ability to comment on whether individual units enact their stated practice. Additionally, we do not review the content of each protocol so we cannot exclude the possibility that the protocols are incorrect or not explicit enough. Ideally, this question could be tested by a cluster randomized trial of protocol-driven general care, but the resources to perform this study and the ethics behind it, could be prohibitive barriers. Lastly, it is possible that we may fail to observe improved outcomes in general ICU patients simply because the "right" protocols have not been developed yet. We believe this is unlikely given the temporal improvements in ICU outcomes that have been observed with time and the magnitude of effect seen in homogenous patient groups, ${ }^{25,44}$ however, this is still a possibility.

Our analysis also may be confounded by not accounting for clustering by ICU in our original sample size calculations. Controlling for this necessitates accounting for the coefficient of variation of the actual mortality between study ICUs, an additional unknown. If we were to now take this into account, we would likely trade more rigorous analysis for less power to detect the expected 3\% difference in hospital mortality (assuming the coefficient of variation for hospital mortality is $>0.1$, Figure 4 ). While our intent is to enroll 6000 participants across 60 ICUs, we plan to monitor longitudinally the observed coefficient of variation for hospital mortality to obtain a better understanding of the magnitude of this potential effect.

In closing, this study will examine the association between the number of care protocols and patient outcome. Further, it will provide a number of important ancillary studies, include an ability to begin to identify what protocol characteristics determine improved practice and a relative weighting of the impact of specific protocols by ICU specialty. This new knowledge in turn can inform design of information systems to automate when possible those practices that have the greatest positive impact on outcomes and costs. This study 


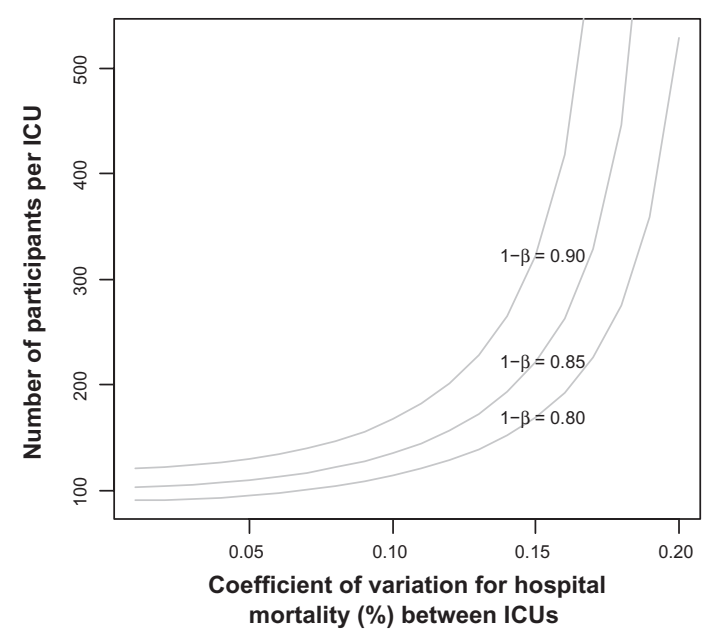

Figure 4 Impact of variation in hospital mortality across study sites given ICU (cluster) recruitment size.

Abbreviation: ICU, intensive care unit.

will generate important information that can be used in the near term by unit and hospital medical directors to inform ICU organization, and in the longer term to determine bridge strategies to improve ICU outcomes in a resource-limited environment.

\section{Acknowledgment}

We acknowledge the leadership of the USCIITG in facilitating the execution of this study and providing invaluable advice on protocol development and execution.

\section{Disclosure}

None of the authors report that they have a significant financial or other competing interest related to the content of this manuscript.

\section{References}

1. Adhikari NK, Fowler RA, Bhagwanjee S, Rubenfeld GD. Critical care and the global burden of critical illness in adults. Lancet. 2010;376(9749): 1339-1346.

2. Pronovost PJ, Angus DC, Dorman T, Robinson KA, Dremsizov TT, Young TL. Physician staffing patterns and clinical outcomes in critically ill patients: a systematic review. JAMA. 2002;288(17):2151-2162.

3. Levy MM, Rapoport J, Lemeshow S, Chalfin DB, Phillips G, Danis M. Association between critical care physician management and patient mortality in the intensive care unit. Ann Intern Med. 2008;148(11): 801-809.

4. Gajic O, Afessa B, Hanson AC, et al. Effect of 24-hour mandatory versus on-demand critical care specialist presence on quality of care and family and provider satisfaction in the intensive care unit of a teaching hospital. Crit Care Med. 2008;36(1):36-44.

5. Kim MM, Barnato AE, Angus DC, Fleisher LF, Kahn JM. The effect of multidisciplinary care teams on intensive care unit mortality. Arch Intern Med. 2010;170(4):369-376.

6. Cooke CR, Watkins TR, Kahn JM, et al. The effect of an intensive care unit staffing model on tidal volume in patients with acute lung injury. Crit Care. 2008;12(6):R134.
7. Lott JP, Iwashyna TJ, Christie JD, Asch DA, Kramer AA, Kahn JM. Critical illness outcomes in specialty versus general intensive care units. Am J Respir Crit Care Med. 2009;179(8):676-683.

8. Kahn JM, Goss CH, Heagerty PJ, Kramer AA, O’Brien CR, Rubenfeld GD. Hospital volume and the outcomes of mechanical ventilation. $N$ Engl J Med. 2006;355(1):41-50.

9. Kahn JM, Ten Have TR, Iwashyna TJ. The relationship between hospital volume and mortality in mechanical ventilation: an instrumental variable analysis. Health Serv Res. 2009;44(3):862-879.

10. Prasad M, Christie JD, Bellamy SL, Rubenfeld GD, Kahn JM. The availability of clinical protocols in US teaching intensive care units. J Crit Care. 2010;25(4):610-619.

11. Umoh NJ, Fan E, Mendez-Tellez PA, et al. Patient and intensive care unit organizational factors associated with low tidal volume ventilation in acute lung injury. Crit Care Med. 2008;36(5):1463-1468.

12. Knaus WA, Draper EA, Wagner DP, Zimmerman JE. APACHE II: a severity of disease classification system. Crit Care Med. 1985;13(10): 818-829.

13. Hayes RJ, Moulton LH. Cluster Randomised Trials. Boca Raton, FL: Chapman and Hall Publishers; 2009.

14. Liang KY, Zeger SL. Regression analysis for correlated data. Annu Rev Public Health. 1993;14:43-68.

15. Hastie T, Tibshirani R. Generalized additive models. Boca Raton, FL: Chapman and Hall Publishers; 1990.

16. Escobar GJ, Greene JD, Gardner MN, Marelich GP, Quick B, Kipnis P. Intra-hospital transfers to a higher level of care: contribution to total hospital and intensive care unit (ICU) mortality and length of stay (LOS). J Hosp Med. 2011;6(2):74-80.

17. Golestanian E, Scruggs JE, Gangnon RE, Mak RP, Wood KE. Effect of interhospital transfer on resource utilization and outcomes at a tertiary care referral center. Crit Care Med. 2007;35(6):1470-1476.

18. Kahn JM, Kramer AA, Rubenfeld GD. Transferring critically ill patients out of hospital improves the standardized mortality ratio: a simulation study. Chest. 2007;131(1):68-75.

19. Johnson JE, Mosher BD, Morrison CA, Schneider PD, Stevens P, Kepros JP. A disciplined approach to implementation of evidence-based practices decreases ICU and hospital length of stay in traumatically injured patients. J Surg Res. 2010;163(2):327-330.

20. Hebert PC, Wells G, Blajchman MA, et al. A multicenter, randomized, controlled clinical trial of transfusion requirements in critical care. Transfusion Requirements in Critical Care Investigators, Canadian Critical Care Trials Group. N Engl J Med. 1999;340(6):409-417.

21. Corwin HL, Gettinger A, Rodriguez RM, et al. Efficacy of recombinant human erythropoietin in the critically ill patient: a randomized, double-blind, placebo-controlled trial. Crit Care Med. 1999;27(11): 2346-2350.

22. Kress JP, Pohlman AS, O'Connor MF, Hall JB. Daily interruption of sedative infusions in critically ill patients undergoing mechanical ventilation. N Engl J Med. 2000;342(20):1471-1477.

23. Kollef MH, Shapiro SD, Silver P, et al. A randomized, controlled trial of protocol-directed versus physician-directed weaning from mechanical ventilation. Crit Care Med. 1997;25(4):567-574.

24. Girard TD, Kress JP, Fuchs BD, et al. Efficacy and safety of a paired sedation and ventilator weaning protocol for mechanically ventilated patients in intensive care (Awakening and Breathing Controlled trial): a randomised controlled trial. Lancet. 2008;371(9607):126-134.

25. [No authors listed]. Ventilation with lower tidal volumes as compared with traditional tidal volumes for acute lung injury and the acute respiratory distress syndrome. The Acute Respiratory Distress Syndrome Network. N Engl J Med. 2000;342(18):1301-1308.

26. Dellinger RP, Levy MM, Carlet JM, et al. Surviving Sepsis Campaign: international guidelines for management of severe sepsis and septic shock: 2008. Crit Care Med. 2008;36(1):296-327.

27. Gillis RC, Weireter LJ Jr, Britt RC, Cole FJ Jr, Collins JN, Britt LD. Lung protective ventilation strategies: have we applied them in trauma patients at risk for acute lung injury and acute respiratory distress syndrome? Am Surg. 2007;73(4):347-350. 
28. Dennison CR, Mendez-Tellez PA, Wang W, Pronovost PJ, Needham DM. Barriers to low tidal volume ventilation in acute respiratory distress syndrome: survey development, validation, and results. Crit Care Med. 2007;35(12):2747-2754.

29. Chaiwat O, Vavilala MS, Philip S, et al. Intraoperative adherence to a low tidal volume ventilation strategy in critically ill patients with preexisting acute lung injury. J Crit Care. 2011;26(2):144-151.

30. Tanios MA, de Wit M, Epstein SK, Devlin JW. Perceived barriers to the use of sedation protocols and daily sedation interruption: a multidisciplinary survey. J Crit Care. 2009;24(1):66-73.

31. O'Connor M, Bucknall T, Manias E. Sedation management in Australian and New Zealand intensive care units: doctors' and nurses' practices and opinions. Am J Crit Care. 2010;19(3):285-295.

32. Levy MM, Dellinger RP, Townsend SR, et al. The Surviving Sepsis Campaign: results of an international guideline-based performance improvement program targeting severe sepsis. Crit Care Med. 2010; 38(2):367-374.

33. Cabana MD, Rand CS, Powe NR, et al. Why don't physicians follow clinical practice guidelines? A framework for improvement. JAMA. 1999;282(15):1458-1465.

34. The McDonell Norms Group. Enhancing the use of clinical guidelines: a social norms perspective. J Am Coll Surg. 2006;202(5):826-836.

35. Berenholtz SM, Pronovost PJ, Lipsett PA, et al. Eliminating catheterrelated bloodstream infections in the intensive care unit. Crit Care Med. 2004;32(10):2014-2020.

36. Kass N, Pronovost PJ, Sugarman J, Goeschel CA, Lubomski LH, Faden R. Controversy and quality improvement: lingering questions about ethics, oversight, and patient safety research. Jt Comm J Qual Patient Saf. 2008;34(6):349-353.
37. Morris AH, Orme J Jr, Truwit JD, et al. A replicable method for blood glucose control in critically Ill patients. Crit Care Med. 2008;36(6):1787-1795.

38. Morris AH, Hirshberg E, Sward KA. Computer protocols: how to implement. Best Pract Res Clin Anaesthesiol. 2009;23(1):51-67.

39. Treggiari MM, Martin DP, Yanez ND, Caldwell E, Hudson LD, Rubenfeld GD. Effect of intensive care unit organizational model and structure on outcomes in patients with acute lung injury. Am J Respir Crit Care Med. 2007;176(7):685-690.

40. Angus DC, Kelley MA, Schmitz RJ, White A, Popovich J Jr. Caring for the critically ill patient. Current and projected workforce requirements for care of the critically ill and patients with pulmonary disease: can we meet the requirements of an aging population? JAMA. 2000; 284(21):2762-2770

41. Nguyen YL, Kahn JM, Angus DC. Reorganizing adult critical care delivery: the role of regionalization, telemedicine, and community outreach. Am J Respir Crit Care Med. 2010;181(11):1164-1169.

42. Barnato AE, Kahn JM, Rubenfeld GD, et al. Prioritizing the organization and management of intensive care services in the United States: the PrOMIS Conference. Crit Care Med. 2007;35(4):1003-1011.

43. Cobb JP. Engineering health in the intensive care unit. Arch Intern Med. 2010;170(4):319-320.

44. Rivers E, Nguyen B, Havstad S, et al. Early goal-directed therapy in the treatment of severe sepsis and septic shock. N Engl J Med. 2001; 345(19):1368-1377. 


\section{Appendix}

\section{Participating centers, listed in alphabetical order by state. The principal investigator's name appears first, then all others are listed in alphabetical order per site.}

ARIZONA: University of Arizona Medical Center, Tucson, AZ, Terence O'Keeffe (PI), Coy Collins; CALIFORNIA: LA County-University of South California Hospital, Los Angeles, CA, Janice Liebler (PI), Ali Ahoui, Anahita Nersiseyan, Usman Shah, Hidenobu Shigemitsu, Nanditha Thaiyananthan; Stanford University Medical Center, Stanford, CA, Joe HSU (PI), Lawrence Ho; CONNECTICUT Bridgeport Hospital, Bridgeport, CT; Yale University Hospital, New Haven, CT, Jonathan M. Siner (PI), Mark D. Siegel; GEORGIA: Emory University Hospital, Atlanta, GA, Greg S. Martin (PI), Craig Coopersmith, Sushma, Cribbs, Annette Esper, Micah Fisher, David Gutteridge, Akrm Abdelrahman, Mona Brown, Sang Lee, Apryl Smith; Grady Memorial Hospital, Atlanta, GA, Greg S. Martin (PI), Craig Coopersmith, Sushma Cribbs, Annette Esper, Micah Fisher, David Gutteridge; ILLINOIS: Northwest Community Hospital, Arlington Heights, IL, Melanie Atkinson (PI), Aimee Draftz, Jackie Durgin, Yelena Rikhman, Jessica Scheckel, Mary Walthers; Saint Francis Hospital, Evanston, IL, Gerald Luger (PI), Carol Downer; University of Illinois Medical Center, Chicago, IL, Ruxana T. Sadikot (PI), Kamran Javaid, Daniel Rodgers, Vibhu Sharma; MARYLAND: John Hopkins Bayview Medical Center, Baltimore, MD, Jon Sevranski (PI), Will Checkley, Romer Geocadin, David Murphy, Dale Needham, Adam Sapirstein, Steven Schwartz, Glenn Whitman, Brad Winters, Addisu Workneh, Sammy Zakaria; John Hopkins Hospital, Baltimore, MD, Jon Sevranski (PI), Will Checkley, Romer Geocadin, David Murphy, Dale Needham, Adam Sapirstein, Steven Schwartz, Glenn Whitman, Brad Winters, Addisu Workneh, Sammy Zakaria; St. Agnes Hospital, Baltimore, MD, Anthony Martinez (PI), Fran Keith; University of Maryland Medical Center, Baltimore, MD, Steven Johnson (PI), Dan Herr, Carl Shanholtz, Arabela Sampaio, Jennifer Titus; NIH Hospital, Bethesda, MD; Suburban Hospital Bethesda, Bethesda, MD, Leo Rotello (PI), Jennifer Anderson; MASSACHUSETTS: Beth Israel Deaconess Medical Center, Boston, MA, Sajid Shahul (PI), Valerie BannerGoodspeed, Michael Howell, Sabina Hunziker, Victoria Nielsen, Jennifer Stevens, Daniel Talmor; Brigham and Women's Hospital, Boston, MA, Namrata Patil (PI), Lisa Chin, Michael Myers, Stanthia Ryan; MAINE: York Hospital, York, Maine; MICHIGAN: University of Michigan
Medical Center, Ann Arbor, MI, Pauline Park (PI), Vivek Arora, James Blum, Kristin Brierley, Jessica DeVito, Elizabeth Jewell, Scott McCardle, Julie McClelland, Deborah Rohner; MINNESOTA: Mayo Clinic Rochester, Rochester, MN, Brian W. Pickering (PI), Jyothsna Gi, Rahul Kashyap, Naman Trivedi; MISSOURI: University of Missouri-Columbia Hospital, Columbia, Missouri; Kansas City VA Hospital, Kansas City, MO, Timothy Dwyer (PI), Kyle Brownback; NEW JERSEY: University of Medicine and Dentistry of New Jersey, Newark, NJ, Steven Chang (PI), Zaza Cohen, Frank Italiano, Zeeshan Kahn, Amee Patrawalla; NEW MEXICO: Presbyterian Healthcare Services, Albequerque, NM, Denise Gonzales (PI), Paul Campbell; NEW YORK: Columbia University Medical Center, New York, NY, David Chong (PI), Matthew Baldwin, Luke Benvenuto, Natalie Yip; Memorial Sloan Kettering Cancer Center, New York, NY; University of Rochester Medical Center, Rochester, NY, Anthony Pietropaoli (PI), Kathleen Faulkner, Timothy Bouck, Ann Marie Mattingly; NORTH CAROLINA: Wake Forest University Health Science, Durham, NC, Peter E. Morris (PI), Lori S. Flores; ECU Hospital, Greenville, NC, Abid Butt, Mark Mazer, Kelly Jernigan; Moses Cone Health, Greensboro, NC, Patrick Wright (PI), Sarah Groce, Jeanette McLean, Arshena Overton; OHIO: Cleveland Clinic, Cleveland, OH, Jorge A. Guzman (PI), Mohammed Abou El Fadl, Tonya Frederick, Gustavo-Cumbo-Nacheli, John Komara; The Ohio State University Medical Center, Columbus, OH, James M. O’Brien (PI), Naeem Ali, Matthew Exline; PENNSYLVANIA: Eastern Regional Medical Center, Cancer Treatment Centers of America, Philadelphia, PA, Jeffrey Hoag (PI), Daniela Albu, Pat McLaughlin; Hahnemann University Hospital, Philadelphia, PA; Hospital of the University of Pennsylvania, Philadelphia, PA, Meeta Prasad (PI), Scott Zuick; TENNESSEE: Meharry Medical College Hospital, Nashville, TN, Richard D. Fremont (PI), Chinenye O. Emuwe, Victor C. Nwazue, Olufemi S. Owolabi; Vanderbilt University Medical Center, Nashville, TN, Bryan Cotton (PI), George Hart, Judy Jenkins; Vanderbilt University Medical Center, Nashville, TN, Todd W. Rice (PI), Tim Girard, Margaret Hays, Susan Morgan; TEXAS: University of Texas-Houston Medical Center, Houston, TX; UTAH: Intermountain Medical Center, Murray, Utah, 
Samuel Brown (PI), Colin Grissom, Russ Miller III, Anita Austin, Heather Gallo, Naresh Kumar, David Murphy;

Abbreviation: PI, principal investigator.
VIRGINIA: Inova Health Systems, Falls Church, VA, Maryann Putman (PI), Joanne Ondrush.

Open Access Journal of Clinical Trials

Dovepress

\section{Publish your work in this journal}

The Open Access Journal of Clinical Trials is an international, peerreviewed, open access journal publishing original research, reports, editorials, reviews and commentaries on all aspects of clinical trial design, management, legal, ethical and regulatory issues, case record form design, data collection, quality assurance and data auditing methodologies. The manuscript management system is completely online and includes a very quick and fair peer-review system, which is all easy to use. Visit http://www.dovepress.com/testimonials.php to read real quotes from published authors.

Submit your manuscript here: http://www.dovepress.com/open-access-journal-of-clinical-trials-journal 